\title{
Paclitaxel-Coated Balloons: Investigation of Drug Transfer in Healthy and Atherosclerotic Arteries - First Experimental Results in Rabbits at Low Inflation Pressure
}

\author{
Nicola Stolzenburg ${ }^{1} \cdot \mathrm{Janni}_{\text {Breinl }}{ }^{1} \cdot$ Stephanie Bienek $^{2} \cdot$ Milosz Jaguszewski $^{3}$. \\ Melanie Löchel $^{2}$ - Matthias Taupitz ${ }^{1}$ - Ulrich Speck ${ }^{1,2}$ • Susanne Wagner ${ }^{1}$ • \\ Jörg Schnorr ${ }^{1}$
}

Published online: 1 April 2016

(C) The Author(s) 2016. This article is published with open access at Springerlink.com

\begin{abstract}
Purpose Beyond antiproliferative properties, paclitaxel exhibits anti-inflammatory activity, which might be beneficial in the local treatment of nonocclusive coronary artery disease. Paclitaxel release and tissue concentrations after paclitaxelcoated balloon treatment using different pressures have not been investigated so far. The aim of the study was to investigate in an atherosclerotic rabbit model whether drug transfer from paclitaxel-coated balloons into the vessel wall is affected by the presence of atherosclerotic lesions and to which extent it depends on the inflation pressure used.

Methods Paclitaxel-coated balloons $\left(3.5 \mu \mathrm{g} / \mathrm{mm}^{2}\right.$ paclitaxel $)$ were inflated with pressures of 1,2 , or 6 atm (60s) in healthy $(n=39)$ and atherosclerotic $(n=22)$ arteries of New Zealand White Rabbits. Paclitaxel content in arterial walls (10 min after interventions) and paclitaxel remaining on balloons after treatment were analyzed using high-performance liquid chromatography.

Results Median paclitaxel tissue concentrations were $829.3 \mu \mathrm{g} / \mathrm{g}$ (IQR $636.5-1487 \mu \mathrm{g} / \mathrm{g}$ ) in healthy and $375.7 \mu \mathrm{g} / \mathrm{g}$ (IQR $169.8-771.6 \mu \mathrm{g} / \mathrm{g})$ in atherosclerotic arteries $(p=0.0002)$. The paclitaxel tissue concentration was dependent on inflation
\end{abstract}

Nicola Stolzenburg

nicola.stolzenburg@charite.de

1 Department of Radiology, Section of Experimental Radiology, Charité - Universitätsmedizin Berlin, Campus Charité Mitte, Charitéplatz 1, 10117 Berlin, Germany

2 InnoRa GmbH, Berlin, Germany

3 Department of Cardiology, Charité - Universitätsmedizin Berlin, Campus Benjamin Franklin, Berlin, Germany pressure ( $1 \mathrm{~atm}$ vs. 2 atm vs. $6 \mathrm{~atm})$ in atherosclerotic arteries ( $p=0.0106)$ but not in healthy arteries $(p \geq 0.05)$.

Conclusions Atherosclerotic lesions impede the transfer of paclitaxel into arterial walls. Higher inflation pressures resulted in an increased paclitaxel transfer in atherosclerotic but not in healthy arteries. However, it is assumed that the tissue concentrations achieved with an inflation pressure of $2 \mathrm{~atm}$ are potentially effective in this model.

Keywords Atherosclerotic plaque · Drug-coated balloon . Inflation pressure $\cdot$ Paclitaxel $\cdot$ Atherosclerotic rabbit model

\section{Introduction}

The use of drug-eluting stents (DES) has significantly reduced the reintervention rate for repeat target lesion revascularization in coronary arteries due to restenosis to below $10 \%$ [1-4]. Following the advent of DES, drug-coated balloons (DCB) were developed as an additional option for local delivery of antiproliferative agents. Since 2009, paclitaxel-coated balloons (PCB) have been successfully used for different indications including local treatment of coronary in-stent restenosis and of stenosis and restenosis in the peripheral arteries [5-9]. Paclitaxel is an antiproliferative drug with anti-inflammatory activity [10-12]. Interestingly, the very short period of DCB inflation is sufficient to transfer enough paclitaxel into the vessel wall for long-term prevention of restenosis [13-15].

In patients with unstable atherosclerotic lesions, delivery of a high enough concentration of paclitaxel from the PCB should be ensured at low inflation pressure. Biological factors such as local inflammatory reactions or intraplaque hemorrhage and mechanical factors may result in weakening and ultimately rupture of vulnerable or unstable plaques $[16,17]$. 
To the best of our knowledge, there are no studies that have investigated whether drug delivery into the atherosclerotic vessel wall is possible at low inflation pressure (1-6 atm). Therefore, we performed the first study to investigate the transfer of paclitaxel from PCB into atherosclerotic vessel walls in a low-cholesterol rabbit model of atherosclerosis using healthy rabbits as controls. Low inflation pressures were used to spare the abnormal but nonstenotic vessel wall.

\section{Materials and Methods}

\section{Rabbit Model of Atherosclerosis}

The experiments were conducted in male New Zealand White Rabbits (Charles River Laboratories International, Inc., Sulzfeld, Germany). To induce atherosclerotic lesions the rabbits were fed a $0.2 \%$ cholesterol diet (Altromin Spezialfutter $\mathrm{GmbH}$, Lage, Germany) ad libitum for five to six months. Atherosclerotic lesion development was enhanced by two subcutaneous injections of heat shock protein (HSP) (HSP $65 \mathrm{kD}$ from Mycobacterium bovis BCG, fragments 180 188, Sigma-Aldrich Chemie GmbH, Steinheim, Germany) [18-22] and a single intravenous (IV) injection of vascular endothelial growth factor (VEGF) (recombinant human VEGF, Sigma-Aldrich Chemie GmbH, Steinheim, Germany) $[23,24]$. The first HSP $(100 \mu \mathrm{g} /$ animal in $1 \mathrm{~mL}$ PBS $)$ injection was given after 4 weeks on the cholesterol diet. The second HSP injection (boost; $100 \mu \mathrm{g} /$ animal in $1 \mathrm{~mL}$ PBS) and the VEGF injection ( $5 \mu \mathrm{g} /$ animal in $0.5 \mathrm{~mL}$ aqua ad iniectabilia) were given after 8 weeks on the cholesterol diet (Fig. 1). Representative histological sections of atherosclerotic lesions induced in the rabbits are shown in Fig. 2.

\section{Paclitaxel-Coated Balloons}

All balloons used in this study for coating with paclitaxel were commercially available high pressure balloons from Invatec (Invatec Technology Center GmbH, Frauenfeld, Switzerland) or Creganna (Creganna Medical, Galway, Ireland). The balloon membranes are made of nylon. The following balloon sizes were used: $3.5-20,4.0-10,4.0-20,5.0-$ 20 , and $6.0-20 \mathrm{~mm}$. All balloons were coated with $3.5 \mu \mathrm{g}$ paclitaxel $/ \mathrm{mm}^{2}$ balloon surface by InnoRa $\mathrm{GmbH}$ (Berlin, Germany), applying the Paccocath ${ }^{\mathrm{TM}}$ composition with the X-ray contrast medium iopromide as excipient. The balloons had a nominal pressure of $7 \mathrm{~atm}$ and a rated burst pressure of approximately $15 \mathrm{~atm}$.

\section{Experimental Design}

The rabbits were treated with PCB 23 to 25 weeks after the initiation of the cholesterol diet. Treatment was performed in 10 rabbits with atherosclerotic lesions induced as described above and in 13 healthy control rabbits. A total of 61 arterial segments (from 10 rabbits with atherosclerotic lesions and 13 healthy control rabbits; Table 1) were treated. At the time of intervention, mean body weight was $3.6 \pm 0.2 \mathrm{~kg}$ in the 13 control rabbits and $4.0 \pm 0.3 \mathrm{~kg}$ in the 10 atherosclerotic rabbits.

Anesthesia was induced with subcutaneous ketamine hydrochloride (Ketamin $10 \%$, WDT, Garbsen, Germany) at a dose of $35 \mathrm{mg} / \mathrm{kg}$ and medetomidine hydrochloride (Domitor ${ }^{\circledR}$, Orion Pharma, Espoo, Finland) at a dose of $0.25 \mathrm{mg} / \mathrm{kg}$. Intravenous maintenance doses were administered during the interventions as required. The rabbits were supplied with oxygen while being anesthetized. Throughout the interventions, ECGs were recorded and oxygen saturation was monitored.

Arterial access was obtained via the right common carotid artery. Immediately before the interventions, all rabbits received $500 \mathrm{IU}$ heparin through the arterial sheath (HeparinNatrium-25,000-ratiopharm ${ }^{\circledR}$, ratiopharm GmbH, Ulm, Germany). Baseline angiography was performed using a Siemens AXIOM Artis zee interventional angiography system following a iopromide bolus injection (Ultravist $370^{\circledR}$, Bayer Health Care, Berlin, Germany). Segments for treatment were selected in the left and right iliac arteries and in the brachiocephalic trunk (BT) (Fig. 3). In the atherosclerotic and healthy animals, PCBs were expanded in a total
Fig. 1 Time course of induction of atherosclerotic plaques in rabbits. The boxes above the arrow list the mean weights of the atherosclerotic rabbits at the beginning and the end of the experiment. Below the time arrow, the boxes list the treatments of the atherosclerotic rabbits by time point in weeks (wk) after the beginning of the cholesterol diet

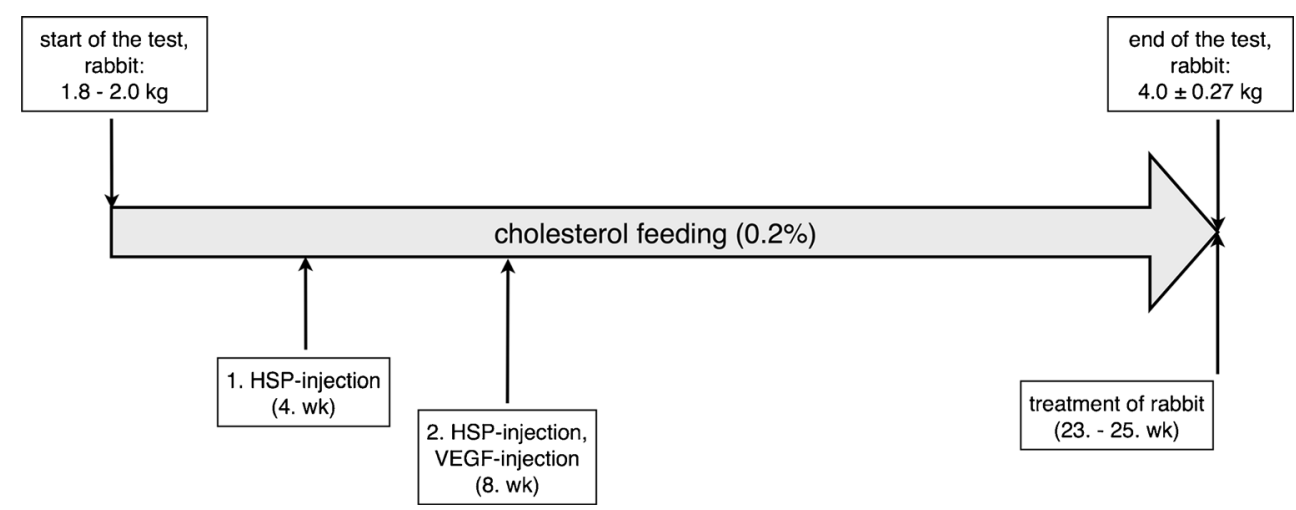




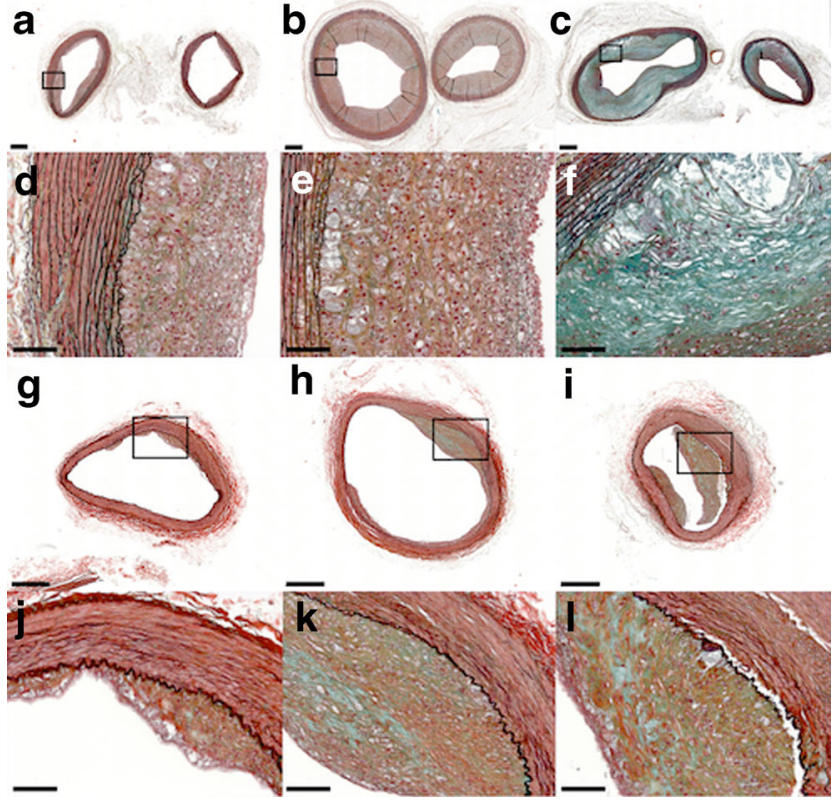

Fig. 2 Representative histological sections of atherosclerotic lesions induced in the used rabbit model. Movat's pentachrome stain of mild to advanced atherosclerotic lesions in the brachiocephalic trunk (a-c left), left common carotid artery (a-c right), and iliac artery (g-i); bar $=500 \mu \mathrm{m}$. The framed areas are magnified in (d-f) and (j-l); bar $=100 \mu \mathrm{m}$

of 22 and 39 arteries, respectively (Fig. 4). The inflation pressures used $(1,2$, or $6 \mathrm{~atm})$ were assigned randomly. The balloon diameters exceeded the reference diameters of the target arteries by $0.5-1 \mathrm{~mm}$ as estimated by angiography (mean overstretch ratio $1.5 \pm 0.3$ ). Estimation of the reference diameters was performed by quantitative measurements using the software included in the angiography system. Oversized balloons were chosen to ensure full circumferential wall contact in spite of low pressures. Balloon inflation time was $60 \mathrm{~s}$.

Ten minutes after the end of the intervention the rabbits were euthanized by IV pentobarbital injection (Narcoren ${ }^{\circledR}$, Merial GmbH, Hallbergmoos, Germany), and the treated arterial segments were removed for measurement of paclitaxel content and concentrations in the vessel walls. In addition, we determined the amount of paclitaxel remaining on the balloons after use.

All experiments were performed in the Institute of Medical Technology \& Research (Rottmersleben, Germany) and the Department of Radiology, Charité - Universitätsmedizin

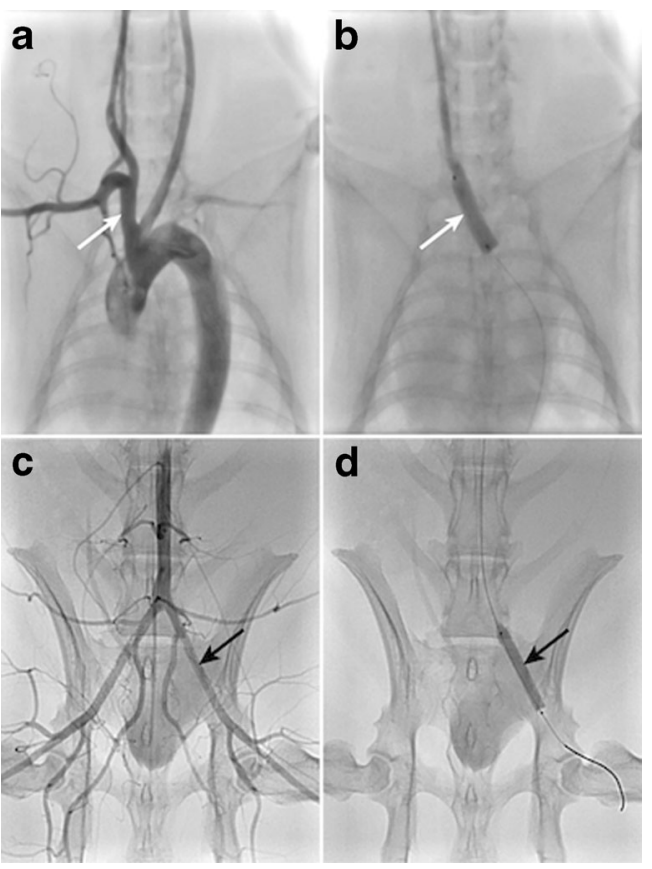

Fig. 3 Overview of arterial sites selected for balloon inflation. Pretreatment angiograms of the brachiocephalic trunk (a, white arrow) and iliac arteries (c, black arrow indicating left iliac artery); inflated balloons in these arteries are depicted in (b) and (d)

Berlin. This study was conducted in accordance with the requirements and guidelines of the EU legislation directive 2010/63/EU and the German Animal Protection Act. The experiments were approved by the local animal protection committee of the Sachsen-Anhalt government and of the LAGeSo Berlin, Germany.

\section{Paclitaxel Analysis}

Paclitaxel was determined by high-performance liquid chromatography (HPLC) with ultraviolet detection. Paclitaxel remaining on the balloons after use was analyzed after extraction with ethanol. For extraction of arteries, a defined volume of ethanol was added, and the samples were treated with ultrasound for $30 \mathrm{~min}$ at room temperature and then centrifuged.

Paclitaxel extracted from balloons was analyzed on a Waters Symmetry C18 column $(5-\mu \mathrm{m}, 250 \mathrm{~mm} \times 4.6 \mathrm{~mm})$ using 55:45 $(v / \mathrm{v})$ acetonitrile $/ 0.005 \mathrm{M}$ potassium phosphate buffer (pH 3.5) as mobile phase for balloon samples and 45:55
Table 1 Percentage of paclitaxel released from balloons at different inflation pressures

\begin{tabular}{lllll}
\hline Inflation pressure [atm] & $\mathrm{n}$ & Healthy arteries [\% of dose] & $\mathrm{n}$ & Atherosclerotic arteries [\% of dose] \\
\hline 1 & 13 & $89.1(88.2-93.1)$ & 6 & $90.2(78.2-95.9)$ \\
2 & 13 & $93.0(90.0-95.1)$ & 10 & $90.5(82.2-94.3)$ \\
6 & 13 & $90.7(71.5-92.7)$ & 6 & $88.2(71.5-92.3)$ \\
$\mathrm{p}^{*}$ & & 0.0649 & & 0.785 \\
\hline
\end{tabular}

Data are given as median and IQR. * $p$-value of Kruskal-Wallis test ( 1 vs. 2 vs. 6 atm) 


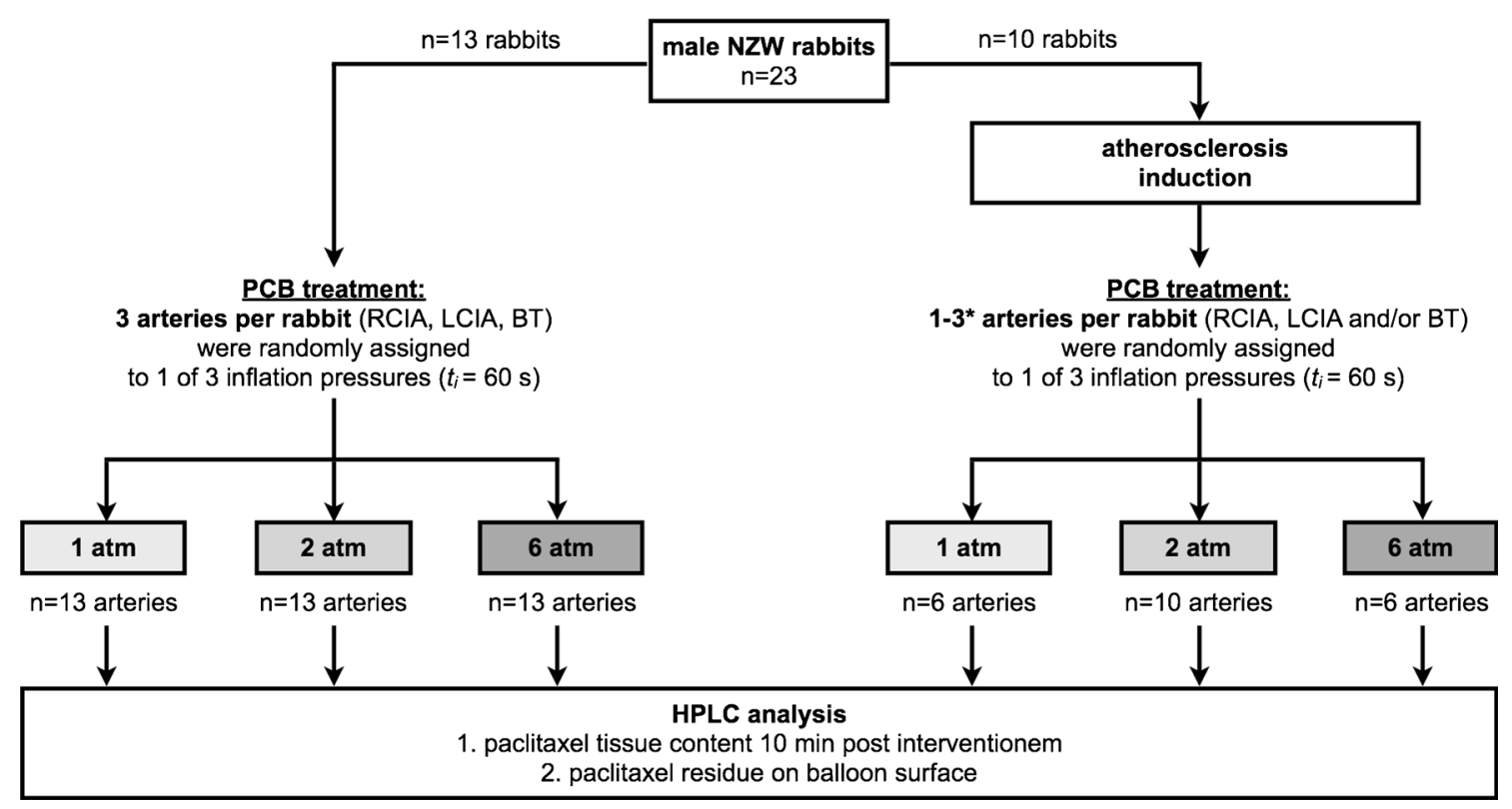

Fig. 4 Experimental design and study groups. Drug transfer from paclitaxel coated balloons (PCB) was investigated in healthy (left side of diagram) and atherosclerotic arteries (right side of diagram) of New Zealand White (NZW) rabbits at 3 different inflation pressures; arteries selected for balloon inflation were the right and left common iliac artery (RCIA, LCIA) and the brachiocephalic trunk (BT). High-performance

$(v / \mathrm{v})$ acetonitrile/potassium phosphate for tissue samples (flow rate: $1 \mathrm{~mL} / \mathrm{min}$ ). Retention time of paclitaxel was $\approx$ 9 min in balloon samples and $\approx 22 \mathrm{~min}$ in tissue samples; detection was performed at $230 \mathrm{~nm}$.

\section{Statistical Analysis}

GraphPad Prism (Version 5.0a for Mac OS X; GraphPad Software, Inc.) was used for statistical analysis. Quantitative data are presented in box-and-whisker plots. Differences between two independent parameters were assessed for significance using the Mann-Whitney U-test. For comparison of more than two independent nonparametric samples, the Kruskal-Wallis test was used. Data are given as median and interquartile range (IQR) or mean \pm standard deviation. The probability of error is given as p. A twosided $p$-value of $<0.05$ is considered to indicate statistical significance.

\section{Results}

\section{Treatment with PCB}

All animals were successfully treated by balloon inflation. During the balloon interventions, only a few rabbits showed minimal variations in heart rate or short mild drops in oxygen saturation. liquid chromatography (HPLC) was used to determine paclitaxel tissue content and paclitaxel remaining on the balloon surface. $t_{i}$, inflation time. * Number of PCB treated arteries varies between 1 and 3 due to concurrent testing of additional substances in atherosclerotic rabbits (data not shown); target sample size for atherosclerotic rabbits was $n=6$ arteries per subgroup

\section{Paclitaxel Release from Balloons}

The median amount of paclitaxel remaining on the balloons $(n=61)$ after use (= proportion of dose not released during the procedure) was $0.29 \mu \mathrm{g} / \mathrm{mm}^{2}$ (IQR $0.21-0.41 \mu \mathrm{g} / \mathrm{mm}^{2}$ ) of balloon surface area. This corresponds to a median paclitaxel release during the procedures of $90.3 \%$ (IQR $86.0-93.7 \%$ ). The median paclitaxel release from balloons used in healthy controls $(n=39$ arteries) was $91.1 \%$ (IQR 87.7-93.1\%) versus $89.8 \%$ (IQR 78.2-94.3\%) in rabbits with atherosclerotic lesions ( $n=22$ arteries; $p=0.7582)$. Furthermore, we compared paclitaxel release between the three arterial segments that were treated: BT $(n=17)$, right iliac artery $(n=22)$, and left iliac artery $(n=22)$. Median paclitaxel release was $91.4 \%$ (IQR 88.9-92.4\%), $89.9 \%$ (IQR 71.1$93.7 \%$ ), and $90.3 \%$ (IQR $83.1-94.7 \%$ ), respectively $(p=0.8689)$. Neither in healthy arteries $(p=0.0649)$ nor in atherosclerotic arteries $(p=0.785)$ was the percentage paclitaxel release significantly dependent on the inflation pressure applied (Table 1).

\section{Paclitaxel in Tissue}

In healthy arterial segments, the median paclitaxel tissue content was $21.16 \mu \mathrm{g}$ (IQR 11.18-33.04 $\mu \mathrm{g}$ ), which corresponds to a median paclitaxel tissue concentration of $829.3 \mu \mathrm{g} / \mathrm{g}$ (IQR $636.5-1487 \mu \mathrm{g} / \mathrm{g}$ ) and $1.90 \%$ (IQR $1.10-2.79 \%)$ of the paclitaxel dose. 
In atherosclerotic arterial segments, median tissue recovery was $8.83 \mu \mathrm{g}$ (IQR 2.52-14.67 $\mu \mathrm{g}$ ), corresponding to a median paclitaxel tissue concentration of $375.7 \mu \mathrm{g} / \mathrm{g}$ (IQR 169.8-771.6 $\mu \mathrm{g} / \mathrm{g}$ ) and $1.00 \%$ (IQR $0.38-1.86 \%$ ) of the paclitaxel dose. The paclitaxel tissue concentration differed significantly between healthy and atherosclerotic arteries $(p=0.0002)$ with concentrations being lower in atherosclerotic arterial segments.

Data of paclitaxel tissue recovery at the different inflation pressures are summarized in Table 2 . No statistically significant relationship was observed between paclitaxel concentrations in healthy arteries and the inflation pressures applied $(p=0.5382)$, whereas in atherosclerotic arteries, an increase in balloon inflation pressure resulted in higher paclitaxel tissue concentrations ( $p=0.0106$, Table 2$)$. At a pressure of 6 atm, tissue concentrations were comparable to those achieved in healthy controls.

Paclitaxel tissue concentrations in healthy and atherosclerotic arteries did not differ significantly between the BT and the right and left iliac arteries $(p=0.9783$ and $p=0.4777)$. Median concentrations in healthy arteries were $927.6 \mu \mathrm{g} / \mathrm{g}$ (IQR 617.4-1424 $\mu \mathrm{g} / \mathrm{g}, n=13$ ) in the BT, $829.3 \mu \mathrm{g} / \mathrm{g}$ (IQR 520.2-1542 $\mu \mathrm{g} / \mathrm{g}, n=13$ ) in the right iliac artery, and $792.7 \mu \mathrm{g} / \mathrm{g}$ (IQR 704.6-1428 $\mu \mathrm{g} / \mathrm{g}$, $n=13)$ in the left iliac artery. In atherosclerotic arteries, median concentrations were $243.0 \mu \mathrm{g} / \mathrm{g}$ (IQR 57.4-1049 $\mu \mathrm{g} / \mathrm{g}$, $n=4), 342.0 \mu \mathrm{g} / \mathrm{g}$ (IQR 166.3-650.3 $\mu \mathrm{g} / \mathrm{g}, n=9$ ), and $472.1 \mu \mathrm{g} / \mathrm{g}$ (IQR 265.6-955.3 $\mu \mathrm{g} / \mathrm{g}, n=9$ ), respectively.

\section{Discussion}

The efficacy and safety of PCB was first demonstrated in clinical settings by Scheller et al. (2006) and Tepe et al.
(2008) [25, 26] and has recently been confirmed by a large randomized multicenter study [27]. In this study (IN.PACT SFA) PCB have been tested for the treatment of symptomatic superficial femoral and proximal popliteal artery disease in comparison to percutaneous transluminal angioplasty (PTA) with uncoated balloon catheters. PCB resulted in persistently lower rates of target lesion revascularization compared with uncoated balloons (2.4\% vs. $20.6 \%$ ) at 12 months [27]. Moreover, the efficacy and safety of PCB (with or without stent in the treated segment) has also been demonstrated in clinical studies for a variety of indications such as in-stent restenosis [13, 28-31], de novo stenosis [32-34], stenosis of small vessels [35, 36] and bifurcation stenosis [37, 38].

In the clinical cases (PTA/PTCA), high pressures of $\geq 6$ atm are usually employed to dilate stenotic arteries. Most animal studies of PCB were also performed using high inflation pressures (6-15 atm) [14, 15, 39-42] in the established model of coronary artery overstretch and stenting in pigs [22, 43, 44]. To the best of our knowledge, there is only one study in which PCB were inflated using low pressure. Cremers et al. [45] used the model of restenosis in pigs, comparing the angiographic parameter of late lumen loss 28 days after interventions. They implanted bare metal stents in the coronary arteries, followed by repeat dilatation with PCB using inflation pressures of 2 and 12 atm. The investigators identified no significant differences in effectiveness between the two pressures used, but they did not measure paclitaxel tissue concentrations in the arterial walls. Therefore, we cannot compare the amount of paclitaxel recovered in the arterial wall following balloon inflation at $2 \mathrm{~atm}$ in our experiments in peripheral arteries of rabbits with the effective amount of paclitaxel transfer in the study of Cremers et al. [45]. In our experiments, only atherosclerotic arteries showed a statistically significant dependence of the paclitaxel tissue concentration on the balloon
Table 2 Paclitaxel recovery in arterial tissue

\begin{tabular}{llllll}
\hline & $\begin{array}{l}p_{i} \\
{[\mathrm{~atm}]}\end{array}$ & $\mathrm{n}$ & {$[\mu \mathrm{g}]$} & $\begin{array}{l}\text { Paclitaxel in tissue } \\
{[\% \text { of dose }]}\end{array}$ & {$[\mu \mathrm{g} / \mathrm{g}]$} \\
\hline \multirow{3}{*}{$\begin{array}{lllll}\text { Healthy } \\
\text { arteries }\end{array}$} & 1 & 13 & $18.64(14.29-31.74)$ & $1.68(1.16-2.76)$ & $792.7(520.2-1211)$ \\
& 6 & 13 & $22.26(18.37-31.55)$ & $2.04(1.69-2.42)$ & $823.6(549.6-2059)$ \\
& $\mathrm{p}^{*}$ & 13 & $20.83(8.78-52.94)$ & $2.07(0.88-5.59)$ & $875.3(756.0-1493)$ \\
Atherosclerotic & 1 & 6 & 0.7906 & 0.6419 & 0.5382 \\
arteries & 2 & 10 & $9.17(3.88-11.22)^{\dagger \dagger}$ & $1.12(0.33-1.77)^{\dagger \dagger}$ & $429.0(132.1-616.6)^{\dagger}$ \\
& 6 & 6 & $16.22(13.04-27.07)$ & $2.65(1.30-4.29)$ & $926.8(644.9-1114)$ \\
& $\mathrm{p}^{*}$ & & 0.0038 & 0.0081 & 0.0106 \\
\hline
\end{tabular}

Data are given as median and (IQR)

$p_{i}$, inflation pressure

${ }^{*} p$-value of Kruskal-Wallis test ( 1 vs. 2 vs. 6 atm)

${ }^{\dagger} p<0.05$

${ }^{\dagger} p<0.01$ in Mann-Whitney test (atherosclerotic vs. healthy arteries at the same inflation pressure) 
inflation pressure used. In healthy vessels, there was only a trend toward higher paclitaxel transfer with increasing pressures.

In the atherosclerotic arterial segments of the rabbits analyzed in our study, mean recovery of paclitaxel for all treatments taken together was $1.00 \%$ of the initial dose on the balloons. This corresponds to a median paclitaxel tissue concentration of $375 \mu \mathrm{g} / \mathrm{g}$ and is 2.2 times lower than the concentration in healthy arteries in the same species. Nevertheless, this concentration is still clearly within the effective range of paclitaxel compared with the tissue concentration known to inhibit neointimal proliferation in pigs $[15,40,42]$. In a study in young domestic pigs, Speck et al. [42] recovered $5.5 \pm 4.7 \%$ of the initial paclitaxel dose in the arterial wall 10 to $30 \mathrm{~min}$ after inflation of PCB $\left(3 \mu \mathrm{g} / \mathrm{mm}^{2}\right)$ at high pressure $(12.1 \pm 1.4 \mathrm{~atm})$. This amount corresponded to a paclitaxel tissue concentration of $133 \pm 114 \mu \mathrm{g} / \mathrm{g}$. In a second study, Speck et al. [42] investigated the amount of paclitaxel in the vessel walls of adult minipigs using the same procedures as in the first study. In the vessel walls of the minipigs, they recovered $21.1 \pm 7.6 \%$ of the initial paclitaxel dose $(534 \pm 285 \mu \mathrm{g} / \mathrm{g}) 10$ to $30 \mathrm{~min}$ after balloon inflation at a pressure of $12.2 \pm 1.3 \mathrm{~atm}$. However, in the second study, the experiments were performed using PCB with premounted stents. The rabbit arteries investigated in our experiments are much thinner than porcine arteries. The mean paclitaxel concentration we recovered in healthy rabbit arteries was $1141 \pm 809 \mu \mathrm{g} / \mathrm{g}$ of tissue (median: $829.3 \mu \mathrm{g} / \mathrm{g}$ ), which is 8.6 times higher than the concentration in young pigs and 2.1 times higher than the concentration in adult minipigs in the studies of Speck et al. The mean tissue concentration of $502 \pm 385 \mu \mathrm{g} / \mathrm{g}$ (median: $375.7 \mu \mathrm{g} / \mathrm{g}$ ) in atherosclerotic arteries was also still above that in domestic pigs [42] and the values reported by Buszman et al. [46], which correspond to tissue concentrations of approximately $153 \pm 155 \mathrm{ng} / \mathrm{mg}$. A recently published pharmakokinetic study by Fernández-Parra et al. (2015) [47] reported paclitaxel tissue concentrations of $632 \pm 126 \mathrm{ng} / \mathrm{mg}$ (mean \pm SEM) in atherosclerotic iliac arteries of rabbits. However, the authors did not mention the inflation pressure applied in their study. The calculated paclitaxel tissue concentration ( $1 \mathrm{~h}$ after angioplasty) was similar to our data. Contrary to our experiments Fernández-Parra et al. determined a paclitaxel tissue concentration of $169 \pm 83 \mathrm{ng} / \mathrm{mg}$ in the arteries of the control animals. This lower concentration might be explained by the use of a different histologic vessel preparation (washing of the arteries after dissection).

Treatment with PCB may be the final step after highpressure predilatation (8-15 atm) of stenotic vessel segments and aims at restoring the original vessel lumen and eliminating the flow obstacle. The initial interventional maneuvers lead to vessel injury, excision or compression and rupture of plaques, and distention of the arterial wall [48-50]. Once a sufficiently large luminal diameter has been restored, use of a PCB may smoothen the luminal surface of the vessel and inhibit neointimal proliferation, and even facilitate plaque regression [51-53]. Furthermore, it is assumed that unstable plaques often have no clinical relevance and may even go unnoticed in coronary angiography [54]. When a PCB is used in the presence of unstable plaques, high-pressure inflation might be harmful. Also, when the original lumen diameter is restored at the site of a significant atherosclerotic lesion, the arterial segment may be susceptible to rupture. In some challenging cases such as unstable plaques or after prior treatment with an atherectomy catheter, it could therefore be advisable to use lower pressures when the aim of treatment is to stabilize lesions, slow further plaque progression and lumen loss, or stimulate metabolic degradation of atherosclerotic material after its compression to the vessel wall. Preventive percutaneous transluminal (coronary) angioplasty (PTCA/PTA) for the treatment of unstable atherosclerotic lesions might be a further indication for the use PCB. Moreover, PCB treatment at low pressure may smoothen luminal surfaces of arteries, which might be beneficial for edge areas after stent implantation.

Interestingly, our experiments confirm that, even with low inflation pressures and low transfer efficacy, high tissue concentrations of paclitaxel are achieved in the delicate arteries of rabbits. Therefore, based on the results of our rabbit experiments, we may assume that a balloon inflation pressure of $2 \mathrm{~atm}$ is more than sufficient to deliver a potentially effective paclitaxel concentration to the vessel wall.

\section{Study Limitations}

Atherosclerotic lesions in rabbits have some resemblance with such lesions in humans. However, no animal model is currently available that simulates all aspects of human atherosclerosis development and the heterogeneity of factors involved, ranging from cellular components to inflammatory reactions or calcifications.

Since the tissue mass and vessel wall thickness of rabbit arteries is markedly lower than that of pig arteries, our results cannot be readily compared with published results obtained in pigs. Further studies have to show whether paclitaxel is effective in treating atherosclerotic lesions in rabbits and ultimately in patients.

\section{Conclusion}

In the present study we investigated paclitaxel transfer from PCB into atherosclerotic vessel walls and compared the results with healthy controls. Specifically, we investigated whether paclitaxel transfer is affected by the applied balloon inflation 
pressures (1, 2, and $6 \mathrm{~atm})$ and the selected artery. Our results are as follows:

1. Atherosclerotic lesions impede the transfer of paclitaxel into arterial walls.

2. Higher inflation pressures increase paclitaxel transfer in atherosclerotic arteries; in healthy arteries the effect of inflation pressure is less obvious or absent.

3. Tissue concentrations achieved with an inflation pressure of 2 atm are potentially effective in this atherosclerotic model.

Acknowledgments This study is part of the doctoral thesis of Janni Breinl. Nicola Stolzenburg and Janni Breinl had full access to all of the data in the study and takes responsibility for the integrity on the data and the accuracy of the data analysis.

\section{Compliance with Ethical Standards}

Conflict of Interest Ulrich Speck is co-investor of specific formulations used on paclitaxel-coated balloons. The other authors declare that they have no conflict of interest.

Funding Sources This work was supported by the Investitionsbank Berlin (IBB) [ProFIT 10,145,732] and co-financed by grants from the European Fund for Regional Development (EFRE).

Open Access This article is distributed under the terms of the Creative Commons Attribution 4.0 International License (http:// creativecommons.org/licenses/by/4.0/), which permits unrestricted use, distribution, and reproduction in any medium, provided you give appropriate credit to the original author(s) and the source, provide a link to the Creative Commons license, and indicate if changes were made.

\section{References}

1. Stone GW, Ellis SG, Cannon L, et al. Comparison of a polymerbased paclitaxel-eluting stent with a bare metal stent in patients with complex coronary artery disease: a randomized controlled trial. J Am Med Assoc. 2005;294(10):1215-23.

2. Morice MC, Serruys PW, Sousa JE, et al. A randomized comparison of a sirolimus-eluting stent with a standard stent for coronary revascularization. N Engl J Med. 2002;346(23):1773-80.

3. Windecker S, Remondino A, Eberli FR, et al. Sirolimus-eluting and paclitaxel-eluting stents for coronary revascularization. N Engl J Med. 2005;353(7):653-62.

4. Babapulle MN, Joseph L, Bélisle P, Brophy JM, Eisenberg MJ. A hierarchical Bayesian meta-analysis of randomised clinical trials of drug-eluting stents. Lancet. 2004;364(9434):583-91.

5. Unverdorben $\mathrm{M}$, Vallbracht $\mathrm{C}$, Cremers B, et al. Paclitaxel-coated balloon catheter versus paclitaxel-coated stent for the treatment of coronary in-stent restenosis. Circulation. 2009;119(23):2986-94.

6. Schmidt A, Piorkowski M, Werner M, et al. First experience with drug-eluting balloons in infrapopliteal arteries: restenosis rate and clinical outcome. J Am Coll Cardiol. 2011;58(11):1105-9.

7. Tepe G, Schmitmeier S, Speck U, Schnorr B, Kelsch B, Scheller B. Advances on drug-coated balloons. J Cardiovasc Surg. 2010;51(1): $125-43$.
8. Byrne RA, Neumann F-J, Mehilli J, et al.. Paclitaxel-eluting balloons, paclitaxel-eluting stents, and balloon angioplasty in patients with restenosis after implantation of a drug-eluting stent (ISAR-DESIRE 3): a randomised, open-label trial. The Lancet 2013;381(9865):461-7.

9. Werk M, Langner S, Reinkensmeier B, et al. Inhibition of restenosis in femoropopliteal arteries: paclitaxel-coated versus uncoated balloon: femoral paclitaxel randomized pilot trial. Circulation. 2008;118(13):1358-65.

10. Kielbassa K, Schmitz C, Gerke V. Disruption of endothelial microfilaments selectively reduces the transendothelial migration of monocytes. Exp Cell Res. 1998;243:129-41.

11. Mirzapoiazova T, Kolosova IA, Moreno L, Sammani S, Garcia JG, Verin AD. Suppression of endotoxin-induced inflammation by taxol. Eur Respir J. 2007;30(3):429-35.

12. Brahn E, Tang C, Banquerigo ML. Regression of Collagen-induced arthritis with taxol, a microtubule stabilizer. Arthritis Rheum. 1994;37(6):839-45.

13. Scheller B, Clever YP, Kelsch B, et al. Long-term follow-up after treatment of coronary in-stent restenosis with a paclitaxel-coated balloon catheter. JACC Cardiovasc Interv. 2012;5(3):323-30.

14. Cremers B, Speck U, Kaufels N, et al. Drug-eluting balloon: very short-term exposure and overlapping. Thromb Haemost. 2009;101(1):201-6.

15. Pósa A, Nyolczas N, Hemetsberger R, et al. Optimization of drugeluting balloon use for safety and efficacy: evaluation of the 2 nd generation paclitaxel-eluting DIOR-balloon in porcine coronary arteries. Catheter Cardiovasc Interv. 2010;76(3):395-403.

16. Moreno PR, Purushothaman KR, Fuster V, et al. Plaque neovascularization is increased in ruptured atherosclerotic lesions of human aorta: implications for plaque vulnerability. Circulation. 2004;110(14): 2032-8.

17. Moreno PR, Purushothaman KR, Fuster V, O'Connor WN. Intimomedial interface damage and adventitial inflammation is increased beneath disrupted atherosclerosis in the aorta: implications for plaque vulnerability. Circulation. 2002;105(21):2504-11.

18. $\mathrm{Xu} \mathrm{Q}$, Dietrich H, Steiner J, et al. Induction of arteriosclerosis in normocholesterolemic rabbits by immunization with heat shock protein 65. Arterioscler Thromb Vasc Biol. 1992;12(7):789-99.

19. Xu Q, Kleindienst R, Waitz W, Dietrich H, Wick G. Increased expression of heat shock protein 65 coincides with a population of infiltrating $\mathrm{T}$ lymphocytes in atherosclerotic lesions of rabbits specifically responding to heat shock protein 65 . J Clin Invest. 1993;91(6):2693-702.

20. Lamb DJ, Ferns GA. The magnitude of the immune response to heat shock protein- 65 following BCG immunisation is associated with the extent of experimental atherosclerosis. Atherosclerosis. 2002;165(2):231-40.

21. Wick $\mathrm{G}$ The heat is on: heat-shock proteins and atherosclerosis. Circulation. 2006;114(9):870-2.

22. Schwartz RS, Huber KC, Murphy JG, et al. Restenosis and the proportional neointimal response to coronary artery injury: results in a porcine model. J Am Coll Cardiol. 1992;19(2):267-74.

23. Celletti FL, Waugh JM, Amabile PG, Brendolan A, Hilfiker PR, Dake MD. Vascular endothelial growth factor enhances atherosclerotic plaque progression. Nat Med. 2001;7(4):425-9.

24. Celletti FL, Hilfiker PR, Ghafouri P, Dake MD. Effect of human recombinant vascular endothelial growth factor 165 on progression of atherosclerotic plaque. J Am Coll Cardiol. 2001;37(8):2126-30.

25. Scheller B, Hehrlein C, Bocksch W, et al. Treatment of coronary instent restenosis with a paclitaxel-coated balloon catheter. N Engl J Med. 2006;355(20):2113-24.

26. Tepe G, Zeller T, Albrecht T, et al. Local delivery of paclitaxel to inhibit restenosis during angioplasty of the leg. N Engl J Med. 2008;358(7):689-99.

27. Tepe G, Laird J, Schneider P, et al. Drug-coated balloon Versus Standard percutaneous transluminal angioplasty for the treatment 
of superficial femoral and popliteal peripheral artery disease. Circulation. 2015;131(5):495-502.

28. Hehrlein C, Dietz U, Kubica J, et al. Twelve-month results of a paclitaxel releasing balloon in patients presenting with in-stent restenosis first-in-man (PEPPER) trial. Cardiovasc Revasc Med. 2012;13(5):260-4.

29. Xu B, Gao R, Wang J, et al. A prospective, multicenter, randomized trial of paclitaxel-coated balloon versus paclitaxel-eluting stent for the treatment of drug-eluting stent in-stent restenosis: results from the PEPCAD China ISR trial. JACC Cardiovasc Interv. 2014;7(2): 204-11.

30. Habara S, Iwabuchi $\mathrm{M}$, Inoue $\mathrm{N}$, et al. A multicenter randomized comparison of paclitaxel-coated balloon catheter with conventional balloon angioplasty in patients with bare-metal stent restenosis and drug-eluting stent restenosis. Am Heart J. 2013;166(3):527-33.

31. Clever YP, Cremers B, Speck U, Dietz U, Böhm M, Scheller B. Influence of a paclitaxel coated balloon in combination with a bare metal stent on restenosis and endothelial function: comparison with a drug eluting stent and a bare metal stent. Catheter Cardiovasc Interv. 2014;84(2):323-31.

32. Liistro F, Porto I, Angioli P, et al. Drug-eluting balloon in peripheral intervention for below the knee angioplasty evaluation (DEBATEBTK): a randomized trial in diabetic patients with critical limb ischemia. Circulation. 2013;128(6):615-21.

33. Liistro F, Grotti S, Porto I, et al. Drug-eluting balloon in peripheral intervention for the superficial femoral artery: the DEBATE-SFA randomized trial (drug eluting balloon in peripheral intervention for the superficial femoral artery). JACC Cardiovasc Interv. 2013;6(12):1295-302.

34. Ali RM, Degenhardt R, Zambahari R, et al. Paclitaxel-eluting balloon angioplasty and cobalt-chromium stents versus conventional angioplasty and paclitaxel-eluting stents in the treatment of native coronary artery stenoses in patients with diabetes mellitus. EuroIntervention. 2011;7(Suppl):KK83-92.

35. Unverdorben M, Kleber FX, Heuer H, et al. Treatment of small coronary arteries with a paclitaxel-coated balloon catheter in the PEPCAD I study: are lesions clinically stable from 12 to 36 months? EuroIntervention. 2013;9(5):620-8.

36. Unverdorben M, Kleber FX, Heuer H, et al. Treatment of small coronary arteries with a paclitaxel-coated balloon catheter. Clin Res Cardiol. 2010;99(3):165-74.

37. Worthley S, Hendriks R, Worthley M, et al. Paclitaxel-eluting balloon and everolimus-eluting stent for provisional stenting of coronary bifurcations: 12-month results of the multicenter BIOLUX-I study. Cardiovasc Revasc Med. 2015;16(7):413-7.

38. Schulz A, Hauschild T, Kleber FX. Treatment of coronary de novo bifurcation lesions with DCB only strategy. Clin Res Cardiol. 2014; 103(6):451-6.

39. Speck U, Scheller B, Abramjuk C, et al. Neointima inhibition: comparison of effectiveness of non-stent-based local drug delivery and a drug-eluting stent in porcine coronary arteries. Radiology. 2006;240(2):411-8.
40. Kelsch B, Scheller B, Biedermann M, et al. Dose response to paclitaxel-coated balloon catheters in the porcine coronary overstretch and stent implantation model. Investig Radiol. 2011;46(4): 255-63.

41. Scheller B, Speck U, Abramjuk C, Bernhardt U, Böhm M, Nickenig G. Paclitaxel balloon coating, a novel method for prevention and therapy of restenosis. Circulation. 2004;110(7):810-4.

42. Speck U, Cremers B, Kelsch B, et al. Do pharmacokinetics explain persistent restenosis inhibition by a single dose of paclitaxel? Circ Cardiovasc Interv. 2012;5(3):392-400.

43. Schwartz RS, Murphy JG, Edwards WD, Camrud AR, Vliestra RE, Holmes DR. Restenosis after balloon angioplasty. A practical proliferative model in porcine coronary arteries. Circulation. 1990;82(6):2190-200.

44. Schwartz RS, Holmes DR. Pigs, dogs, baboons, and man: lessons for stenting from animal studies. J Interv Cardiol. 1994;7(4):355-68.

45. Cremers B, Toner JL, Schwartz LB, et al.. Inhibition of neointimal hyperplasia with a novel zotarolimus coated balloon catheter. Clin Res Cardiol. 2012;101(6):469-76.

46. Buszman PP, Milewski K, Zurakowski A, et al.. Experimental evaluation of pharmacokinetic profile and biological effect of a novel paclitaxel microcrystalline balloon coating in the iliofemoral territory of swine. Catheter Cardiovasc Interv. 2014;83(2):325-33.

47. Fernández-Parra R, Laborda A, Lahuerta C, et al. Pharmacokinetic study of paclitaxel concentration after drugeluting balloon angioplasty in the iliac artery of healthy and atherosclerotic rabbit models. J Vasc Interv Radiol. 2015;26(9):1380-7.e1.

48. Virmani R, Farb A, Burke AP. Coronary angioplasty from the perspective of atherosclerotic plaque: morphologic predictors of immediate success and restenosis. Am Heart J. 1994;127(1):163-79.

49. Ramsdale DR, Morris JL. If rotablator is useful, why don't we use it? Heart. 1997;78(Suppl 2):36.

50. Saffitz JE, Totty WG, McClennan BL, Gilula LA. Percutaneous transluminal angioplasty. Radiological-pathological correlation. Radiology. 1981;141(3):651-4.

51. Werk M, Albrecht T, Meyer DR, et al. Paclitaxel-coated balloons reduce restenosis after femoro-popliteal angioplasty: evidence from the randomized PACIFIER trial. Circ Cardiovasc Interv. 2012;5(6): 831-40.

52. Kleber FX, Schulz A, Waliszewski M, et al.. Local paclitaxel induces late lumen enlargement in coronary arteries after balloon angioplasty. Clin Res Cardiol. 2015;104(3):217-25.

53. Siablis D, Kitrou PM, Spiliopoulos S, Katsanos K, Karnabatidis D. Paclitaxel-coated balloon angioplasty versus drug-eluting stenting for the treatment of infrapopliteal long-segment arterial occlusive disease: the IDEAS randomized controlled trial. JACC Cardiovasc Interv. 2014;7(9):1048-56.

54. Falk E, Nakano M, Bentzon JF, Finn AV, Virmani R. Update on acute coronary syndromes: the pathologists' view. Eur Heart J. 2013;34(10):719-28. 